\title{
BMJ Open Not quite a doctor, but should I help? A qualitative exploration of medical students' attitudes towards responding to medical emergencies that occur in the public domain
}

\author{
Jessica Ying-Yi Xie, Rachael Frost, ${ }^{\circledR}$ Richard Meakin
}

To cite: Xie JY-Y, Frost R, Meakin R. Not quite a doctor, but should I help? A qualitative exploration of medical students' attitudes towards responding to medical emergencies that occur in the public domain. BMJ Open 2019:9:e028035. doi:10.1136/ bmjopen-2018-028035

- Prepublication history for this paper is available online. To view these files, please visit the journal online (http://dx.doi org/10.1136/bmjopen-2018028035).

Received 4 December 2018 Revised 28 February 2019 Accepted 11 March 2019
Check for updates

(C) Author(s) (or their employer(s)) 2019. Re-use permitted under CC BY-NC. No commercial re-use. See rights and permissions. Published by BMJ.

Research Department of Primary Care and Population Health, University College London, London, UK

Correspondence to

Dr Rachael Frost;

rachael.frost@ucl.ac.uk

\section{ABSTRACT}

Objective To explore medical students' views on and experiences of responding to out-of-hospital medical emergencies.

Setting University College London (UCL).

Participants 11 UCL Medical School students.

Study design Qualitative.

Methods and outcome measures We carried out 11 one-to-one semistructured interviews, with participant validation and reflective work. The data were analysed using thematic analysis.

Results Three core themes were identified. (1) 'We Did Debate a Bit: Should We Go? Should We Not?'-Students' decisions to respond were based on the appearance of the casualty; the presence and actions of bystanders; witnessing the incident; self-perceived competence, confidence and knowledge; and personal experiences and feelings associated with medical emergencies. (2) 'It Would Represent the Medical Profession Well if We Did Step In and Help'Students felt that they had an ethical and/or professional duty to help. (3) 'No One Should Die Because of a Lack of... Basic Life-Saving Techniques'-Students felt that medical school training alone had not sufficiently prepared them to respond to out-of-hospital medical emergencies. Improvements to training were suggested: integrating first aid/response training into the horizontal (systems-based) modules; teaching both common and less common medical emergencies and presentations; training that is led by experienced first responders and that increases students' exposure to out-of-hospital medical emergencies; and providing more revision training sessions.

Conclusions Students felt that medical school training could be improved to better prepare them for responding to out-of-hospital medical emergencies, and wanted clarification on whether or not they have an ethical and/or professional duty to help. Further mixed-methods research using a larger sample needs to be carried out to confirm whether findings are transferable to other UK medical schools.

\section{INTRODUCTION}

A medical emergency may be defined as any situation in which appropriate and rapid
Strengths and limitations of this study

- This study provided in-depth exploration of medical students' thoughts and feelings towards their response to out-of-hospital medical emergencies.

- The credibility of the study was increased through participant validation and data triangulation (semistructured interviews and a reflective journal).

- Each author contributed their interpretation of the data, ensuring that one researcher's preconceptions did not dominate the analysis and that a wide range of alternative perspectives on the data were considered, to allow more insightful interpretations to be drawn from the data.

- A small sample of students were recruited from a single medical school, limiting the range of experiences and opinions that were gathered and reducing the transferability of the findings to other medical schools.

- Theoretical saturation was reached, implying that sufficient data were obtained regarding University College London medical students' views and strengthening the study's credibility.

medical intervention is essential to prevent death or serious injury.

Up to 140000 deaths in England and Wales could be prevented each year if appropriate first aid is performed quickly. ${ }^{1}$ Since every minute delay of cardiopulmonary resuscitation (CPR) on a cardiac arrest victim decreases their chance of survival by $2.3 \%,{ }^{2}$ effective early bystander intervention during the wait for the ambulance service to arrive at the scene has the potential to save lives. ${ }^{3-5}$ According to a national survey conducted by St John Ambulance, ${ }^{6}$ only 1 in 10 bystanders would administer CPR in the public domain.

The General Medical Council (GMC) states that qualified doctors in the UK must be competent to diagnose a medical emergency and provide immediate support. ${ }^{7}$ General 
practitioners are contractually obliged under the General Medical Service to provide emergency treatment during core hours for any persons within their practice's area. ${ }^{8}$ UK medical students do not have a legal or professional duty to help, nor the same ethical obligation as a qualified doctor. ${ }^{9}$

Most UK medical schools provide emergency care training. ${ }^{10}$ Students at UCL Medical School (UCLMS) receive training in adult, paediatric and obstetric basic life support (BLS), adult and paediatric advanced life support and critical care in the hospital setting. One UK study ${ }^{11}$ found that only one-third of 115 medical students were able to perform the first step of BLS (assessing the scene for danger) correctly. Towards the end of undergraduate medical training, students appear to be more confident: the results of a study conducted in Finland showed that $70 \%$ of 71 of penultimate-year medical students and $85.7 \%$ of 56 final-year medical students claimed to be confident in their BLS abilities. ${ }^{12}$ Confidence appears to be directly correlated with the number of cardiac arrests that students have witnessed, suggesting experience is an important part of training. ${ }^{13} \mathrm{~A}$ survey conducted at a Norwegian medical school found that most final-year medical students had had non-interventional experiences of medical emergencies (eg, 72\% of 76 students had observed defibrillation); however, fewer students had provided emergency medical care outside of the teaching environment (eg, $47 \%$ had participated in CPR). ${ }^{14}$

When considering whether to provide CPR in clinical practice, UK doctors and medical students report making judgements on the basis of diagnosis and prognosis; the age of the patient; quality of life; opinions of doctors and other medical staff; the wishes of the patient and relevant others; and doctors' beliefs and values. ${ }^{15}$ One key finding of a Japanese study ${ }^{16}$ was that medical students may be unwilling to perform mouth-to-mouth resuscitation because they fear that they will contract a disease.

Most studies that have investigated medical students' physical and emotional reactions to medical emergencies are quantitative studies that have been conducted over 10 years ago outside the UK and are predominantly focused in the hospital setting. There has been little research in the area of UK medical students responding to out-of-hospital medical emergencies, whereby out-of-hospital refers to a non-clinical setting with limited access to medical personnel and resources and response refers to a person's thoughts, emotional reaction and physical action that immediately follow encountering the situation. We therefore aimed to explore UK medical students' views on experiences of responding to out-of-hospital medical emergencies. We hoped that our study findings would reveal areas where students feel they lack knowledge and/ or skills, which could identify areas for future improvement in education.

\section{Box 1 Categorisation of participants}

Participants were categorised according to the level of their exposure to out-of-hospital medical emergencies.

- Category 1: participants who currently have greater exposure to out-of-hospital medical emergencies because they participate, or have participated, in activities (eg, with St. John Ambulance) that increase their exposure.

- Category 2: participants who do not currently have greater exposure to out-of-hospital medical emergencies because they have never participated in activities that increase their exposure.

Participants were then subcategorised based on their experiences.

- Subcategory A: participant intervened in at least one out-of-hospital medical emergency.

- Subcategory B: participant witnessed, but did not intervene in, at least one out-of-hospital medical emergency.

- Subcategory C: participant has no experience (ie, has never witnessed or intervened in an out-of-hospital medical emergency).

\section{METHODS}

We carried out a qualitative study, using semistructured interviews, participant validation and a reflective journal to collect data. We chose to conduct interviews rather focus groups as we were interested in individual experiences (rather than exploring group norms and social interactions) and wanted to be able to probe more deeply regarding these. ${ }^{17} \mathrm{JX}$ (a medical student studying the Medical Science with Primary Healthcare intercalated Bachelor of Science $[\mathrm{iBSc}]$ ) carried out all data collection and led the analysis. The study was conducted at UCLMS over 6 months. Participants were recruited using purposive, convenience and snowball sampling.

Twelve University College London (UCL) medical students were invited to participate. One student declined because of the time commitment of the study (one interview lasting up to $45 \mathrm{~min}$ and participant validation, which would take $\sim 15 \mathrm{~min})$. Ten participants were sampled through convenience (students known to JX) and purposively according to their medical emergency exposure levels (categorisation in box 1). Two participants (10 and 11) were sampled by snowball sampling, as they were introduced to JX through a previous participant (09). Participants who were interested in participating were e-mailed brief screening questions about their exposure to out-of-hospital medical emergencies and experiences of witnessing or intervening in out-of-hospital medical emergencies in order to categorise them prior to recruitment. Eleven students provided written informed consent and completed the study. Recruitment ceased when no new codes were generated during coding of the last three transcripts, signifying that theoretical saturation had been reached.

\section{Interviews}

JX carried out all face-to-face semistructured interviews between February 2018 and March 2018 using a topic guide developed in conjunction with RM and RF, which was refined in light of data collection. 


\section{Box 2 Proposed theoretical scenario}

You are walking down a busy street. A person across the road to you collapses. No one stops to help.

Interview topics included features of a medical emergency; experiences of responding to medical emergencies; legal, professional and ethical obligations to intervene; and training. Interviews focused solely on experiences of out-of-hospital medical emergencies rather than incidents that had been encountered in a teaching environment. Participants who had no personal experience of intervening in out-of-hospital medical emergencies were asked how they believe they would respond in a theoretical situation (see box 2) in order to understand their potential response and the decision-making process behind this.

Interviews lasted on average $35 \mathrm{~min}$ and were audio recorded.

Field notes were made by JX during the interview in a reflective journal. For example, JX noted the need to rephrase questions to minimise ambiguity to improve data collection and considered the possibility of interviewer influence on participants' responses.

\section{Patient and public involvement}

JX presented the study to 10 Medical Science with Primary Healthcare iBSc students to confirm the relevance of the study to medical students.

Participants did not contribute to the design, planning or management of the study. However, one participant directed JX to recruit a further two participants (snowball sampling).

All 11 participants received a summary of the study findings and 6 out of the 11 participants responded to the request for participant validation.

\section{Analysis}

All aspects of participants' verbal narrative that were recorded were transcribed verbatim by JX. Theoretical saturation was judged to have occurred after completion of the eighth interview (as JX commenced analysis alongside data collection). ${ }^{18}$ Three additional interviews were conducted to confirm this.

Thematic analysis was used to identify core themes. ${ }^{19}$ JX familiarised herself with the data by listening to audio recordings and rereading the transcripts, field notes and validation feedback. Codes were derived both deductively from the topic guide and inductively from the data. ${ }^{20}$ Only data relevant to the research question were coded. ${ }^{21}$ JX coded the full dataset using NVivo V.11. ${ }^{22}$ A subset of transcripts was independently coded by RF (project supervisor with expertise in qualitative methods). JX and RF compared codes to gather different perspectives on the emerging data. ${ }^{23}$ Emerging codes were compared against existing codes and the codes were refined. Previous transcripts were recoded using the revised codes, until

\begin{tabular}{|c|c|c|}
\hline $\begin{array}{l}\text { Participant } \\
\text { identification } \\
\text { number }\end{array}$ & $\begin{array}{l}\text { Year of } \\
\text { medical } \\
\text { school } \\
\text { training (out } \\
\text { of } 6 \text { years) }\end{array}$ & $\begin{array}{l}\text { Category, subcategory and } \\
\text { activity (if applicable) }\end{array}$ \\
\hline 01 & 2 & $2 \mathrm{~A}$ \\
\hline 02 & 3 & 1A-first aider (volunteer) \\
\hline 03 & 3 & $\begin{array}{l}1 \mathrm{~A}-\text { first aider (volunteer and } \\
\text { paid work) }\end{array}$ \\
\hline 04 & 3 & $\begin{array}{l}1 \mathrm{~A}-\text { first aider (volunteer) } \\
\text { and prehospital care training }\end{array}$ \\
\hline 05 & 3 & $\begin{array}{l}1 A \text { and } B-\text { first aider (paid } \\
\text { work) }\end{array}$ \\
\hline 06 & 3 & $1 \mathrm{~A}-$ prehospital care training \\
\hline 07 & 5 & $\begin{array}{l}1 \mathrm{~A} \text { and } \mathrm{B}-\text { paediatric } \\
\text { life-saving training and } \\
\text { wilderness medicine training }\end{array}$ \\
\hline 08 & 5 & $\begin{array}{l}1 \mathrm{~A} \text { and } \mathrm{B}-\text { member of a } \\
\text { wilderness medicine society, } \\
\text { first aider (volunteer) }\end{array}$ \\
\hline 09 & 1 & $2 \mathrm{C}$ \\
\hline 10 & 1 & $2 \mathrm{C}$ \\
\hline 11 & 1 & 2B \\
\hline
\end{tabular}

no new codes emerged, ensuring thorough coding and more robust analysis. ${ }^{24}$ Codes with common elements were grouped together under subthemes, which were subsequently categorised under core themes. ${ }^{18} \mathrm{JX}$ examined the coherence of the data within each theme and the credibility of each theme in relation to the dataset, and ensured that there was no overlap between themes. The authors independently reviewed the themes and a final interpretation was agreed.

\section{Participant validation}

All 11 participants were e-mailed the finalised themes and a description of each subtheme and JX's interpretation of their individual interview. Six participants responded to participant validation. All of these participants agreed with the study findings and JX's interpretations of their interview. No subsequent changes were made to the themes.

\section{RESULTS}

Eleven participants were interviewed, who reported a range of first aid/response experiences (see table 1). Three core themes were identified (table 2). Of those who had responded to an out-of-hospital medical emergency, four had provided assistance when someone had collapsed by performing BLS, calling for help and/or putting the patient in the recovery position. Three participants had helped people who had sustained traumatic injury by applying pressure to the injured area to stop bleeding. Two participants had encountered out-of-hospital medical 


\begin{tabular}{|c|c|c|}
\hline & Core theme & Subthemes \\
\hline \multirow[t]{3}{*}{1} & \multirow{3}{*}{$\begin{array}{l}\text { 'We Did Debate a } \\
\text { Bit: Should We Go? } \\
\text { Should We Not?' }\end{array}$} & What is the situation? \\
\hline & & $\begin{array}{l}\text { Knowledge, competence and } \\
\text { confidence }\end{array}$ \\
\hline & & $\begin{array}{l}\text { Personal experiences and } \\
\text { feelings associated with } \\
\text { medical emergencies }\end{array}$ \\
\hline \multirow[t]{2}{*}{2} & \multirow{2}{*}{$\begin{array}{l}\text { 'It Would Represent } \\
\text { the Medical } \\
\text { Profession Well if We } \\
\text { Did Step In and Help' }\end{array}$} & $\begin{array}{l}\text { Obligations: legal, ethical and } \\
\text { professional }\end{array}$ \\
\hline & & $\begin{array}{l}\text { Expectations of medical } \\
\text { students }\end{array}$ \\
\hline \multirow[t]{4}{*}{3} & \multirow{4}{*}{$\begin{array}{l}\text { 'No One Should Die } \\
\text { Because of a Lack } \\
\text { of... Basic Life- } \\
\text { Saving Techniques' }\end{array}$} & How useful is training? \\
\hline & & Training responsibility \\
\hline & & What training should look like \\
\hline & & $\begin{array}{l}\text { Differences between } \\
\text { individuals }\end{array}$ \\
\hline
\end{tabular}

emergencies but did not offer their help or intervene in the situation in any way, and two had never witnessed an out-of-hospital medical emergency.

Half of the participants who had responded to an out-of-hospital medical emergency had intervened while on duty in a voluntary or paid first aid role and half had intervened on encountering the situation while off duty. Participants who responded as a first aider on duty reported having never responded alone to situations. One participant who was not on duty also described responding to someone who had collapsed as part of a group of medical students. However, five students had responded to out-of-hospital medical emergencies alone. Two participants also described experiences of managing bystanders, for example, asking them to step away, call for help and/or provide assistance in BLS.

\section{'We Did Debate a Bit: Should We Go? Should We Not?' (07, 5th year, $1 A$ and $B$ ) \\ What is the situation?}

All participants described how they would assess the situation before deciding whether or not to intervene. In particular, participants stated that they would observe the age and physical appearance of the victim.

if it was a child, I would probably [intervene]... a sick child is often a situation that unsettles people quite a lot... Elderly people as well, because they're obviously quite vulnerable $(08,5$ th year, $1 \mathrm{~A}$ and $\mathrm{B})$

A few participants considered the potential risks to the safety of others and themselves, if they were (not) to intervene.

If you see that the situation is dangerous for you... you shouldn't go and help... your safety is priority (09, 1st year, 2C)
Most participants felt that they would be more likely to intervene if no one appears to be helping the victim, or if bystanders' (lack of) action(s) appear to be worsening the situation and if they felt that they could improve the situation by intervening.

if I was... the only [or] the first person at the scene, I would [be more likely to] help... than if there... were other people [already there] $(07,5$ th year, $1 \mathrm{~A}$ and $\mathrm{B})$

When medically trained professionals were already present at the scene of the medical emergency, participants reported that they would be less likely to intervene as the situation was already being managed.

I've walked past in things before where people are already helping... the ambulance were already there... I wouldn't... help because I'd probably just be in the way $(07,5$ th year, $1 \mathrm{~A}$ and $\mathrm{B})$

\section{Knowledge, competence and confidence}

Most participants felt that their knowledge of, and competency and confidence in providing, emergency care somewhat depended on the extent of their medical and/or emergency care training.

medical students have varying degrees of knowledge and confidence [depending on] their [year of] studies $(09,1$ st year, 2C)

Increased exposure to medical emergencies appeared to be the main driver behind participants' confidence. Participants with greater exposure to out-of-hospital medical emergencies (category 1; see box 1) and/or in the later years of medical school training tended to feel highly knowledgeable and competent, and believed that they would intervene.

I think confidence is really achieved by exposure $(08$, 5 th year, $1 \mathrm{~A}$ and $\mathrm{B}$ )

'I would be quite comfortable if I had to provide immediate medical care $(08,5$ th year, $1 \mathrm{~A}$ and $\mathrm{B})$

Likewise, those with less exposure to out-of-hospital medical emergencies (category 2; see box 1) and/or who were in the earlier years of medical school training tended to feel that their knowledge and competence were low.

[hesitation, says whilst nervously laughing] honestly I-I don't feel like I could help anyone with the knowledge that I have now (01, 2nd year, 2A)

Those who did not feel confident providing emergency medical care alone stated that they would seek 'the right help' from fellow 'medical students [with] previous experience in [responding to] medical emergencies' (11, 1st year, 2C, participant validation).

A few felt that, if one feels that their competence is low, it would be best to not intervene to avoid potentially making the situation worse. 
[It is] good to act on the... student's... ability... if the student can't perform first aid, it would be better for them not to help and make things worse $(01,2$ nd year, 2A)

\section{Personal experiences and feelings associated with medical} emergencies

Only one student felt that the experience of responding to an out-of-hospital medical emergency had not had an emotional impact on them. For other students, a range of positive feelings (excitement and feeling useful) and negative feelings (overwhelmed, helpless, embarrassment, burden, stress, doubt and fear) were reported in association with first-time involvement in an out-of-hospital medical emergency.

it makes you feel quite responsible... I felt useful (06, 3rd year, $1 \mathrm{~A}$ and $\mathrm{B}$ )

On responding to a patient in cardiac arrest: 'I was not ready for this. It was very overwhelming' $(05,3 \mathrm{rd}$ year, 1A)

A few felt that their experiences were an opportunity for learning and personal development.

the first time... you always panic because you don't know what you're doing, but then you learn from each mistake, get better over time $(03,3$ rd year, $1 \mathrm{~A})$

Participants who had positive experiences believed that they would be able to help if they were required to in the future.

knowing that I have dealt with some medical incidents... I feel more reassured that I will make a positive difference if I was to step in (02, 3rd year, $1 \mathrm{~A})$

Participants who were given a theoretical situation (see box 2) stated they would perform BLS if necessary. However, they did not acknowledge the potential physical, mental and emotional stress of the situation.

I would go and see what's wrong, like, if they're breathing or not; do the basic... life support... if they need it $(11,1$ st year, 2B)

\section{'It Would Represent the Medical Profession Well if We Did Step In and Help' (01, 2nd year, 2A) \\ Obligations: legal, ethical and professional}

All participants agreed that UK medical students have no legal obligation to help in a medical emergency, but disagreed on the existence of a Good Samaritan law in the UK. ${ }^{25}$ Few were confident about the implications of the law.

We're not legally obliged to respond to emergencies $(07,5$ th year, $1 \mathrm{~A}$ and $\mathrm{B})$

there's the concept of Good Samaritan and law sort of stuff, that, in theory, protects those who respond to emergencies... it's quite recent legislation here... I'm a bit, sort of, deficient in facts on this $(08,5$ th year, $1 \mathrm{~A}$ and $\mathrm{B})$

All participants believed that medical students have an ethical obligation to respond appropriately. Participants reported that they would be more likely to intervene if they felt that they would be able to improve the situation.

we have a moral obligation (05, 3rd year, $1 \mathrm{~A})$

the ambulance were already there..., so I [did not offer my] help because I'd probably just be in the way $(07,5$ th year, $1 \mathrm{~A}$ and $\mathrm{B})$

However, for a few, this ethical obligation for a person to help extended to all citizens-not just medical students.

There's a moral obligation for anyone to help another human if they know they can help (03, 3rd year, 1A)

Some felt that medical students also have a professional duty to intervene, as representatives of the medical profession and/or medical school.

when you go and help somebody... you... represent the Medical School... it makes not only yourself look helpful [but] the Medical School as well (09, 1st year, 2C)

\section{Expectations of medical students}

All participants felt that the public expected them to respond to medical emergencies. There were mixed views of public expectations of medical students' competencies.

some members of the public... would expect us to just gawk and standby, whereas others would think 'Well, you're basically doctors, why don't you do something?!' (08, 5th year, $1 \mathrm{~A}$ and $\mathrm{B})$

Most participants believed that the medical school and the GMC expect medical students to respond medical emergencies, but within the limits of their competency.

The Medical School would expect you to go help (09, 1st year, 2C)

'No One Should Die Because of a Lack of... Basic Life-Saving Techniques' (03, 3rd year, 1A)

How useful is training?

While a mix of theory and practical training had equipped participants with the skills required to make potentially life-saving interventions, a few highlighted that this had not prepared them for the possible emotional trauma of encountering medical emergencies, since reactions were context dependent.

I wasn't prepared at all. I was not ready for this. It was very overwhelming $(05,3$ rd year, $1 \mathrm{~A})$

One participant believed that anyone, including people not trained in first aid/response or medicine, can help 
in an emergency, perhaps implying that training is not always necessary to make a positive difference.

if...'help' is seeing an ill patient and calling an ambulance... anyone should go and help (06, 3rd year, $1 \mathrm{~A}$ and $\mathrm{B})$

\section{Training responsibility}

Most thought that the responsibility to train medical students to be prepared to intervene in out-of-hospital medical emergencies lies with the medical school, but one participant was unsure.

I think the Medical School bears a burden $(08,5$ th year, $1 \mathrm{~A}$ and $\mathrm{B}$ )

I don't know whose responsibility it should be $(06$, 3rd year, $1 \mathrm{~A}$ and $\mathrm{B}$ )

However, opinions were divided on, to what extent, if the medical school provides insufficient training, students then become responsible for ensuring that they are prepared.

If students aren't adequately trained, this should foremost be identified by the Medical School to teach them before they seek extra-curricular training $(07$, 5 th year, $1 \mathrm{~A}$ and $\mathrm{B}$ participant validation)

JX: do you think that students should take the responsibility in the own hands... to [ensure that they are] prepare $[d]$... for these situations? Student: I think by all means $(08,5$ th year, $1 \mathrm{~A}$ and $\mathrm{B})$

\section{What training should look like}

Most participants expressed complete dissatisfaction with emergency care training delivered by the medical school, describing it as illogical and lacking depth.

we were informally taught recovery position... by [a medical student] in a maths lecture? Why wasn't it taught with CPR? (02, 3rd year, 1A)

I don't remember that being massively comprehensive $(05$, 3rd year, $1 \mathrm{~A})$

All participants suggested ideas for improving the training provided by the medical school. A few students wanted first aid/response training to be integrated into the horizontal (systems-based) modules because they believed that this would increase their understanding of the management of medical emergencies. One student expressed the desire to be taught a greater range of potential presentations, in order to be prepared for realistic situations. A few students thought that teaching should be delivered by individuals who have more experience of being first responders and to be offered more opportunities to gain greater understanding and/or exposure to out-of-hospital medical emergencies (eg, through a prehospital care module). Most students wanted more revision sessions to consolidate their knowledge and skills. getting a London Ambulance service paramedic to teach us, or someone with pre-hospital experience, who can give tips of the trade, would be a benefit. (04, 3rd year, 1A)

\section{Differences between individuals}

Personal interest in emergency medicine was a strong influence on seeking extracurricular training, which in turn is likely to have resulted in increased exposure and experiences, knowledge and skills.

my clinical interest... is acute emergency medicine, especially outside of the hospital... it's... more than natural [for me] to go on courses and further my skills and skills, beyond... what the Medical School teaches $(08,5$ th year, $1 \mathrm{~A}$ and $\mathrm{B})$

\section{DISCUSSION}

Prior to this study, little was known about whether UK medical students feel that they should respond to out-of-hospital medical emergencies. Our qualitative study findings revealed that students believe they have ethical and/or professional obligations to respond within the limits of their competency. However, they did not always feel knowledgeable or confident about this, and this related strongly to their prior experience(s) and training. Medical school training was felt to have significant limitations with regards to preparing students for these situations. In particular, students expressed dissatisfaction with the frequency, and comprehensiveness, of teaching.

These findings are consistent with previous studies. One study ${ }^{13}$ found that increased exposure to medical emergencies (in this case witnessing more than five cardiac arrests) was the main driver behind students' confidence to provide BLS. Students who are confident in their skills are more likely to offer their help. ${ }^{16}$ However, our study explored the broader context of how students' personal interests and emotions guide their helping behaviour. Students' competence and self-confidence in performing CPR appears to decline over time, ${ }^{26}$ which is consistent with our study's participants wanting more revision sessions throughout the curriculum to increase skill retention.

\section{Strengths and limitations}

In the semistructured interviews, some participants struggled to recall details of past events, for example, the thought process involved in their response. However, this method allowed for deep exploration of students' feelings and experiences, whereas quantitative methods, such as surveys, would fail to capture in-depth contextual data and it would have been difficult to collect observational data on this topic. JX (a medical student), RF (a health services researcher) and RM (senior clinical academic) each contributed their interpretation of the data, ensuring that a range of interpretations were considered. 
The credibility of the study findings was increased through participant validation and triangulation of interview and reflective journal data. ${ }^{27}$

Our sample of students varied according to year of study and exposure to emergencies, ensuring that we captured a wide variety of perspectives. The convenience nature of the sample may mean that we did not capture all experiences; however, we felt we had reached theoretical saturation after the eighth interview. As we only sampled students studying at UCLMS, the study findings may not be transferable to other medical schools with different approaches to first aid/response training.

JX was a UCL medical student. Therefore, participants were able to freely use medical jargon, allowing for a more organic verbal narrative. However, students (particularly those in lower years) may have been reluctant to share thoughts and/or experiences that may portray them negatively to JX or be regarded as concerning behaviour by the GMC or medical school. To limit this, JX reassured participants' anonymity preinterview and postinterview and emphasised that there would be no 'right' or 'wrong' answers to any of the questions.

\section{Implications}

It is only possible to draw tentative conclusions from a small qualitative study. Our study findings suggest that medical students understand that they do not have a legal duty to help. ${ }^{9}$ Students demonstrated their abilities to judge the situation and consider how their actions could potentially impact the situation. However, they may need to be reminded, perhaps by the GMC and/or the medical school, that their ethical and professional duty as medical students is to only act with the limits of their competence to avoid potentially causing harm to others. ${ }^{28}$

Students believe it is important that emergency care training is included on the undergraduate medical curriculum. However, some felt that extracurricular training (eg, training provided by St John Ambulance) is more comprehensive, with regards to teaching a wider range of potential situations. When students shared how they felt medical school emergency care training could be improved, they thought it would be particularly helpful for training to be integrated into horizontal (systemsbased) modules; to learn about both common and less common acute medical emergency presentations; to be offered more opportunities to gain greater exposure to out-of-hospital medical emergencies, for example, providing all students with the opportunity to work shadow paramedics in a prehospital care module, which is currently a student-selected component with limited spaces for enrolment; and to have more revision sessions throughout their undergraduate medical training.

Future research needs to encompass a larger sample of medical students from multiple UK medical schools. Further quantitative research would highlight the prevalence of these views and the extent to which there is a need to improve undergraduate medical training in this area.

\section{CONCLUSIONS}

Medical school emergency care training could be further developed to better improve students' knowledge, confidence and competence in responding to out-of-hospital medical emergencies. Students feel this could be achieved through increasing the frequency of training and providing more opportunities for exposure to out-of-hospital medical emergencies. Students expressed the need for clearer guidance regarding their duties to respond to medical emergencies, which could be reiterated throughout training to minimise the risk of any misunderstanding. Further mixed-methods research on this topic using a larger, more heterogenous sample needs to be carried out to confirm the findings of this study and whether they are transferable to other UK medical schools.

Acknowledgements We would like to thank Dr Tamar Koch (academic supervisor) and Dr Surinder Singh (Primary Health Care iBSc course lead) for helping us to develop our ideas, resulting in the creation of this study's research question. Gratitude must also be expressed to Dr Ann Griffin (Director of the Research Department of Medical Education [RDME] of UCLMS), for granting us permission to interview UCL medical students. Finally, we are thankful to all the study participants, who donated their time and shared their experiences and thoughts.

Contributors JY-YX was the main author who designed the study, collected and analysed the data and was the main author for the write-up. RF was the project supervisor with expertise in qualitative methods. RM was the chief investigator. Both RM and RF helped with every stage of the study, in particular the designing and analysis stages and provided input in the write-up. All authors have read and approved the final manuscript.

Funding The authors have not declared a specific grant for this research from any funding agency in the public, commercial or not-for-profit sectors.

Competing interests None declared.

Patient consent for publication Not required.

Ethics approval Ethical approval to carryout this study was received from University College London Research Ethics Committee (ref.12471/001). JX was prepared to signpost participants who found the interview upsetting to UCL student support.

Provenance and peer review Not commissioned; externally peer reviewed.

Data sharing statement This is a qualitative study and therefore the data generated are not suitable for sharing beyond that contained within the report. Further information can be obtained from the corresponding author.

Open access This is an open access article distributed in accordance with the Creative Commons Attribution Non Commercial (CC BY-NC 4.0) license, which permits others to distribute, remix, adapt, build upon this work non-commercially, and license their derivative works on different terms, provided the original work is properly cited, appropriate credit is given, any changes made indicated, and the use is non-commercial. See: http://creativecommons.org/licenses/by-nc/4.0/.

\section{REFERENCES}

1. McLaren E. Death \{Registrations $\}$ SSummary $\}$ Tables $\}$ - $\{$ England $\}$ and $\{$ Wales\}. 2012 http://www.ons.gov.uk/ons/rel/vsob1/death-regsum-tables/2011-final-/index.html

2. Larsen MP, Eisenberg MS, Cummins RO, et al. Predicting survival from out-of-hospital cardiac arrest: a graphic model. Ann Emerg Med 1993;22:1652-8.

3. Holmberg M, Holmberg S, Herlitz J. Swedish Cardiac Arrest Registry. Factors modifying the effect of bystander cardiopulmonary resuscitation on survival in out-of-hospital cardiac arrest patients in Sweden. Eur Heart J 2001;22:511-9.

4. Iwami T, Kitamura T, Kawamura T, et al. Chest compression-only cardiopulmonary resuscitation for out-of-hospital cardiac arrest with public-access defibrillation: a nationwide cohort study. Circulation 2012;126:2844-51. 
5. Stiell I, Nichol G, Wells G, et al. Health-related quality of life is better for cardiac arrest survivors who received citizen cardiopulmonary resuscitation. Circulation 2003;108:1939-44.

6. St John Ambulance. Survey reveals low first aid confidence. 2011 https://www.sja.org.uk/sja/training-courses/training-news/dk-surveynews.aspx (cited 10 Nov 2018).

7. General Medical Council. Outcomes For Graduates 2018 [Internet]. 2018:17-18 https://www.gmc-uk.org/-/media/documents/dc11326outcomes-for-graduates-2018_pdf-75040796.pdf

8. Boyton C. Good Samaritan acts. BMJ Careers [Internet]. 2007 http:// careers.bmj.com/careers/advice/Good_Samaritan_acts

9. Medical Defence Union. Good Samaritan acts [Internet]. 2017 https:// www.themdu.com/guidance-and-advice/guides/good-samaritanacts (cited 10 Nov 2018).

10. Phillips PS, Nolan JP. Training in basic and advanced life support in UK medical schools: questionnaire survey. BMJ 2001;323:22-3.

11. Wheeler C. Pre-hospital emergency skills for medical students. Emergency Med J 2015;32:1001.2-2.

12. Niemi-Murola L, Mäkinen M, Castren M. ECCE Study Group. Medical and nursing students' attitudes toward cardiopulmonary resuscitation and current practice guidelines. Resuscitation 2007;72:257-63.

13. Freund Y, Duchateau FX, Baker EC, et al. Self-perception of knowledge and confidence in performing basic life support among medical students. Eur J Emerg Med 2013;20:193-6.

14. Casey WF. Experience of medical students in cardiopulmonary resuscitation. Lancet 1983;1:1444-5.

15. Tyrer F, Williams $M$, Feathers $L$, et al. Factors that influence decisions about cardiopulmonary resuscitation: the views of doctors and medical students. Postgrad Med J 2009;85:564-8.

16. Shibata K, Taniguchi T, Yoshida M, et al. Obstacles to bystander cardiopulmonary resuscitation in Japan. Resuscitation 2000;44:187-93.
17. Britten N. Qualitative Research: Qualitative interviews in medical research. BMJ 1995;311:251-3.

18. Strauss A, Corbin JM. Basics of qualitative research: Grounded theory procedures and techniques. Newbury Park, CA, US: Sage Publications, Inc, 1990.

19. Braun V, Clarke V. Using thematic analysis in psychology. Qual Res Psychol 2006;3:77-101.

20. Stuckey $\mathrm{H}$. The second step in data analysis: Coding qualitative research data. Journal of Social Health and Diabetes 2015:03:007-10.

21. Maguire M, Delahunt B. Doing a Thematic Analysis: A Practical, Step-by-Step Guide for Learning and Teaching Scholars. All Irel J Teach Learn High Educ 2017;8:3351-14.

22. QSR International Pty Ltd. NVivo qualitative data analysis Software, 2015.

23. Adams J, Bateman B, Becker F, et al. Effectiveness and acceptability of parental financial incentives and quasi-mandatory schemes for increasing uptake of vaccinations in preschool children: systematic review, qualitative study and discrete choice experiment. Health Technol Assess 2015;19:1-176.

24. Hewitt-Taylor J. Use of constant comparative analysis in qualitative research. Nurs Stand 2001;15:39-42.

25. Social Action, Responsibility and Heroism Act 2015 [Internet] 2015:2-4 https://www.legislation.gov.uk/ukpga/2015/3

26. Avisar L, Shiyovich A, Aharonson-Daniel L, et al. Cardiopulmonary resuscitation skills retention and self-confidence of preclinical medical students. Isr Med Assoc J 2013;15:622-7.

27. Fusch PI, Ness LR. Are We There Yet? Data Saturation in Qualitative Research. Qual Rep 2015;20:1408-16.

28. General Medical Council. Achieving good medical practice: guidance

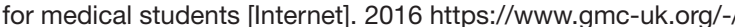
media/documents/achieving-good-medical-practice-0816_pdf66086678.pdf 